\title{
Thermoelectric Simple and Multilayers Prepared by Laser
}

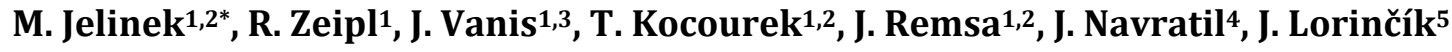 \\ ${ }^{1}$ Institute of Physics ASCRv.v.i., Prague, Czech Republic \\ ${ }^{2}$ Faculty of Biomedical Engineering, Czech Technical University in Prague, Kladno, Czech Republic \\ ${ }^{3}$ Institute of Photonics and Electronics ASCR, v.v.i., Prague, Czech Republic \\ ${ }^{4}$ Institute of Macromolecular Chemistry ASCR v.v.i., Prague, Czech Republic \\ ${ }^{5}$ Research Centre Rez, Husinec-Rez, Czech Republic \\ Email: "jelinek@fzu.cz
}

Received 21 October 2015; accepted 5 January 2016; published 11 January 2016

\begin{abstract}
Thermoelectric layers as $\mathrm{Bi}_{2} \mathrm{Te}_{3}, \mathrm{Yb}_{0.19} \mathrm{Co}_{4} \mathrm{Sb}_{12}, \mathrm{FeSb}_{2} \mathrm{Te}, \mathrm{Ce}_{0.1} \mathrm{Fe}_{0.7} \mathrm{Co}_{3.3} \mathrm{Sb}_{12}$ and $\mathrm{FeSb}_{2} \mathrm{Te}_{\mathrm{Ce}} \mathrm{Ce}_{0.1} \mathrm{Fe}_{0.7} \mathrm{Co}_{3.3} \mathrm{Sb}_{12}$ multilayers were prepared by Pulsed Laser Deposition (PLD). Smooth, nano-crystalline, stoichiometric layers were synthetized in a classical PLD arrangement or in a special off-axis PLD arrangement, followed by Rapid thermal annealing. Results of physical characterizations such as morphology-Atomic Force Microscope, Scanning Electron Microscope, composition-Energy Dispersive X-ray analysis, crystallinity-X-ray Diffraction, separation of multilayers-Secondary of ion beam mass spectroscopy SIMS and study of thermoelectric properties such as the thermoelectric figure of merit ZT, in-plane electrical resistivity, Seebeck coefficient and thermal conductivity are presented. For thermal conductivity measurement a newly developed Atomic force thermal microscope (AFMTh) was tested. Results obtained on the single layers compared to multi-layered structures are discussed.
\end{abstract}

\section{Keywords}

PLD, RTA, Laser Deposition, Annealing, Thermoelectric Layer, Harman, $\mathrm{FeSb}_{2} \mathrm{Te}, \mathrm{Ce}_{0.1} \mathrm{Fe}_{0.7} \mathrm{Co}_{3.3} \mathrm{Sb}_{12}$

\section{Introduction}

The compounds with skutterudite structure $(\mathrm{Co}, \mathrm{Ni}, \mathrm{Fe})(\mathrm{P}, \mathrm{Sb}, \mathrm{As})_{3}$ have been identified during the last decades as the most attractive materials for intermediate temperature thermoelectric power applications. $\mathrm{CoSb}_{3}$-based skutterudites have attracted research interest mainly because of their low thermal conductivity, high Seebeck coefficient and high electrical conductivity. A good thermoelectric material should have a large Seebeck coefficient to produce required voltage, low thermal conductivity to keep the heat at the junction and low electrical resistivity to minimize Joule heating. The key advantage of skutterudites is their possible high figure of merit ZT. The filling voids with $\mathrm{Yb}$ can reduce lattice thermal conductivity without altering the power factor. The quality

\footnotetext{
${ }^{*}$ Corresponding author.
}

How to cite this paper: Jelinek, M., Zeipl, R., Vanis, J., Kocourek, T., Remsa, J., Navratil, J. and Lorinčík, J. (2016) Thermoelectric Simple and Multilayers Prepared by Laser. Journal of Materials Science and Chemical Engineering, 4, 52-64. 
of thermoelectric layers is expressed by dimensionless figure of merit ZT (thermoelectric efficiency) given by the formula: $\mathbf{Z T}=\left(\mathbf{S}^{2} \cdot \boldsymbol{\sigma} \cdot \mathbf{T}\right) / \boldsymbol{\lambda}$, where $\mathrm{S}, \sigma, \mathrm{T}$ and $\lambda$ are the Seebeck coefficient, the electrical conductivity, the ambient temperature and the thermal conductivity, respectively. The term $S^{2} \sigma$ is called power factor and can be used for evaluation of the thermoelectric material if thermal conductivity $\lambda$ is unknown. Experimentally achieved values on $\mathrm{CoSb}_{3}$ bulk alloys typically remain below ZT $<0.5$ and thus below the value required for most practical applications. A great improvement of thermoelectric properties was proven by preparing materials in the form of a low dimensional systems, such as thin layers, superlattices or multi-layered structures. In this contribution, we used laser for creation of $\mathrm{Bi}_{2} \mathrm{Te}_{3}, \mathrm{Yb}_{\mathrm{x}} \mathrm{Co}_{4} \mathrm{Sb}_{12}, \mathrm{FeSb}_{2} \mathrm{Te}, \mathrm{Ce}_{0.1} \mathrm{Fe}_{0.7} \mathrm{Co}_{3.3} \mathrm{Sb}_{12}$ single layers and $\mathrm{FeSb}_{2} \mathrm{Te} / \mathrm{Ce}_{0.1} \mathrm{Fe}_{0.7} \mathrm{Co}_{3.3} \mathrm{Sb}_{12}$ multi-layered structures and studied their transport and thermoelectric properties. We present also description of the scanning thermal microscope technique for characterization of relative thermal conductivity and obtained experimental results.

\section{Experimental}

\subsection{Deposition}

Thermoelectric thin films were prepared using PLD in two different arrangements (Figure 1(a) and Figure 1(b)). In the first arrangement (Figure 1(a)) the substrate, fixed on the resistively heated holder, is not moving. It allows the substrate, placed perpendicular to plasma plume, to be resistively heated. Kinetic energy of particulates ablated from target can be up to $1 \mathrm{keV}$ (depends on energy density of laser beam), and crystallisation of growing, stoichiometric layer can be reached. To decrease number of droplets in the films a special measures, as target-substrate distance, energy density, etc. has to be applied. In the off-axis configuration (Figure 1(b), the rotating substrate is placed perpendicular to the PLD target, usually on the side (off the axis) of plasma plume. In our case, we placed (after some variations) the rotating substrate directly into the plume. In the off-axis scheme the energy of condensate particulates is lower compared to 1a) scheme. Substrate has to be rotated to reach homogeneous coating, and therefore cannot be heated. Because our off-axis setup forbids direct substrate heating, we utilized Rapid thermal annealing (RTA) method to crystallize the layers after deposition process. Several annealing temperature profiles were tested from $5 \mathrm{~s}$ burst to 20 minutes burst. Reached temperature ranged from $150^{\circ} \mathrm{C}$ to $500^{\circ} \mathrm{C}$.

\subsection{Films Characterization}

For determination of surface quality (roughness, homogeneity) two methods were used: Alpha-step IQ mechanical profilometer (KLA TENCOR Co.) and optical microscope integrated in atomic force microscope Solver NEXT (NT-MDT).The crystalline properties were measured using X-Ray diffraction (XRD), which utilizes parallel beam geometry, detector scan with the stationary sample (rotating around the normal to the surface), and the glazing angle of incidence (GAOI). To determine stoichiometry a Wavelength dispersive $\mathrm{x}$-ray spectroscopy (WDS) was used. Temperature dependencies of in-plane electrical resistivity and the Seebeck coefficient were studied in the range from room temperature to $180^{\circ} \mathrm{C}$. In-plane electrical resistivity was studied by a conventional DC van der Pauw's method with the experimental error of about $10 \%$. Thermoelectric figure of merit (ZT) was studied at room temperature by the Harman technique using so-called variable thickness approach mathematically equivalent to measurement with different current density. For relative thermal conducti-

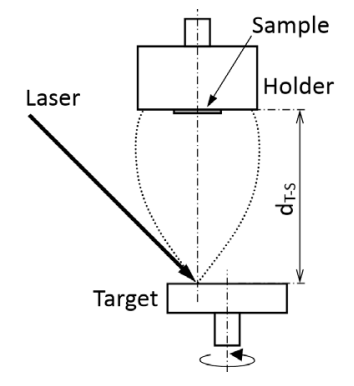

(a)

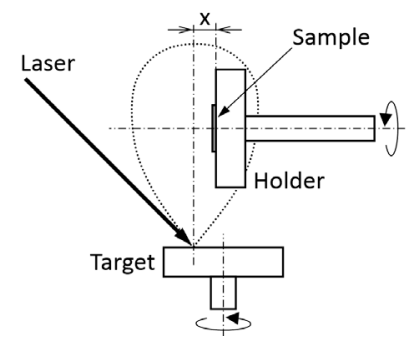

(b)

Figure 1. (a) Classical PLD arrangement; (b) off-axis PLD arrangement. 
vity characterization of thin thermoelectric layers and multi-layered structures we proposed a method using an Atomic force scanning thermal microscope. The method requires a very smooth films to reach good contact of electrodes to measured film. Study of elements separation in multilayers was checked using SIMS. The SIMS measurements were done using Cameca IMS $7 \mathrm{f}$ instrument. $\mathrm{Cs}^{+}$primary ion beam with impact energy $5 \mathrm{keV}$, current 2 nA. Positively charged secondary ions ${ }^{16} \mathrm{O}^{+},{ }^{140} \mathrm{Ce}^{+},{ }^{133} \mathrm{Cs}^{28} \mathrm{Si}^{+},{ }^{133} \mathrm{Cs}^{54} \mathrm{Fe}^{+},{ }^{133} \mathrm{Cs}^{59} \mathrm{Co}^{+},{ }^{133} \mathrm{Cs}^{121} \mathrm{Sb}^{+}$, ${ }^{133} \mathrm{Cs}^{130} \mathrm{Te}^{+}$were registered. The pressure in the analysis chamber during the measurement was $7 \times 10^{-8} \mathrm{~Pa}$.

\section{Results and Discussion}

\section{1. $\mathrm{Bi}_{2} \mathrm{Te}_{3}$ Single Layers}

Films were created according scheme in Figure 1(a). The AFM and profilometer films roughness $\mathrm{R}_{\mathrm{a}}$ for various energy density $E$ (for $T_{S}=360^{\circ} \mathrm{C}$ ) and various substrate temperatures $T_{S}$ (for $E=3 \mathrm{~J} \cdot \mathrm{cm}^{-2}$ ) were measured. The smoothest layers $(0.4-1.4 \mathrm{~nm})$ were prepared at $200^{\circ} \mathrm{C}, 3 \mathrm{~J} \cdot \mathrm{cm}^{-2}$, in argon atmosphere of $13 \mathrm{~Pa}$, for $40 \mathrm{~mm}$ target- substrate distance. There was the excess of $\mathrm{Bi}(\mathrm{Bi} / \mathrm{Te} \sim 0.76)$ compared to target $\mathrm{Bi} / \mathrm{Te} \sim 0.67)$. Layers prepared from $\mathrm{Bi}_{2} \mathrm{Te}_{3}$ target were found to be $\mathrm{N}$-type semiconductor. The studied layers shoved semi-metallic behaviour i.e. flat or slightly increasing electrical resistivity with increasing temperature. The in-plane electrical resistivity about $1 \mathrm{~m} \Omega \cdot \mathrm{cm}$ and the Seebeck coefficient of about $-61 \mu \mathrm{V} \cdot \mathrm{K}^{-1}$ were measured at room temperature. Low room temperature ZT about 0.13 was determined by Harman method. From the ZT we estimated thermal conductivity approximately $0.86 \mathrm{~W} \cdot \mathrm{K}^{-1} \cdot \mathrm{m}^{-1}$. The measured values for the layers prepared from $\mathrm{Bi}_{2} \mathrm{Te}_{3} \operatorname{target}$ correspond to published results [1].

\section{2. $\mathrm{Yb}_{0.19} \mathrm{Co}_{4} \mathrm{Sb}_{12}$ Layers}

Hot pressed $\mathrm{Yb}_{0.19} \mathrm{Co}_{4} \mathrm{Sb}_{12}\left(=\mathrm{Yb}_{12} \mathrm{Co}_{24.7} \mathrm{Sb}_{74.17}\right)$ target was used for PLD (configuration Figure 1(a)) of $\mathrm{Yb}$ filled $\mathrm{CoSb}_{3}$ layers, created in argon ambient in range from 0.5 to $13 \mathrm{~Pa}$, for target substrate distance $4 \mathrm{~cm}$ and $6 \mathrm{~cm}$, and energy densities $\mathrm{E}$ from 0.8 to $5 \mathrm{~J} \cdot \mathrm{cm}^{-2}$. The lowest roughness $\mathrm{R}_{\mathrm{a}}$ of about $5 \mathrm{~nm}-10 \mathrm{~nm}$ was reached for low laser fluencies $\left(0.8 \mathrm{~J} \cdot \mathrm{cm}^{-2}\right)$, but mechanical quality of films was poor and growth rate low (about 0.1 A/pulse). The roughness measured by AFM was substantially higher (about 3 times) compared to profilometer measurements. For $\mathrm{d}_{\mathrm{T}-\mathrm{S}}=4 \mathrm{~cm}$ we observed a deficit of $\mathrm{Yb}$ and surplus of Co. Sb was transferred from target to film roughly stoichiometric (as measured by EDX). Films created at $0.8 \mathrm{~J} \cdot \mathrm{cm}^{-2}$ exhibited generally poor stoichiometry and mechanical properties. Optimal conditions and stoichiometric transport were found for $\mathrm{d}_{\mathrm{T}-\mathrm{S}}=$ $6 \mathrm{~cm}, 4 \mathrm{~J} \cdot \mathrm{cm}^{-2}, \mathrm{~T}_{\mathrm{S}}$ of $270^{\circ} \mathrm{C}$ and $13 \mathrm{~Pa}$ of Ar. XRD shows that the films were nano-crystalline with CoSb $\mathrm{Struc}_{3}$ ture. Grain size was in the range of $\sim 50-80 \mathrm{~nm}$. Film roughness $\mathrm{R}_{\mathrm{a}}$ moved from $5 \mathrm{~nm}$ to $40 \mathrm{~nm}$. For creation of multilayers or superlattices the films roughness has to be further improved using mechanical fan or off- axis geometrical arrangement.The temperature dependencies of measured in-plan electrical resistivity and the Seebeck coefficient are depicted in Figure 2. All tested layers were found to be $\mathrm{N}$ conductivity type (negative sign of the Seebeck coefficient). The $\mathrm{Yb}_{0.19} \mathrm{Co}_{4} \mathrm{Sb}_{12}$ layers shoved typical semiconducting behaviour-the decreasing electrical resistivity with increasing temperature, with the room temperature value of about $7 \mathrm{~m} \Omega \cdot \mathrm{cm}$. Positive temperature dependencies were measured for the Seebeck coefficient (increasing absolute value of the Seebeck coefficient with temperature) with room temperature absolute values of about $-112 \mu \mathrm{V} \cdot \mathrm{K}^{-1}$ for polycrystalline $\mathrm{Yb}_{0.19} \mathrm{Co}_{4} \mathrm{Sb}_{12}$ layers (S-74). For the sintered $\mathrm{Yb}_{0.19} \mathrm{Co}_{4} \mathrm{Sb}_{12}$ bulk samples there were a different values of resistivity about $0.61 \mathrm{~m} \Omega \cdot \mathrm{cm}$ and Seebeck coefficient about $-141 \mu \mathrm{V} \cdot \mathrm{K}^{-1}$ published elsewhere [2], but some difference is expected when comparing bulk 3D material with a thin layer or other low dimensional system. We can observe also the change of resistivity and Seebeck coefficient for layers exhibiting small difference in films stoichiometry. By Harman method we measured room temperature ZT value around 0.04. The measured value is very close to the method resolution limit. For the $\mathrm{Yb}_{0.19} \mathrm{Co}_{4} \mathrm{Sb}_{12}$ layers $\mathrm{ZT}$ 's of about 0.26 were presented in literature [2]. From ZT we estimated thermal conductivity of $1.3 \mathrm{~W} \cdot \mathrm{K}^{-1} \cdot \mathrm{m}^{-1}$. The calculated power factor $\left(\mathrm{S}^{2} / \mathrm{R}\right)$ is shown in Figure 3.

\subsection{Single $\mathrm{FeSb}_{2}$ Te Layers}

It is supposed [3] that new ternary skutterudites phases as $\mathrm{FeSb}_{2} \mathrm{Te}$ with enhanced thermoelectric properties may be used for fabrication of thermoelectric elements which substantially improve the efficiency of resulting thermoelectric device. 


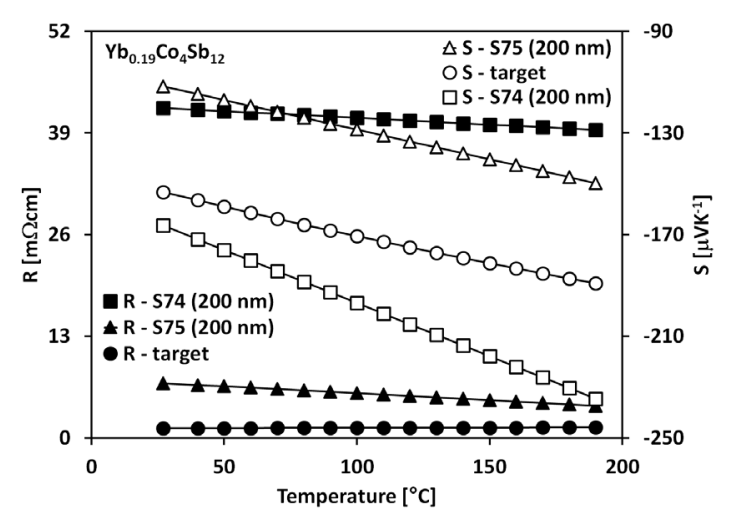

Figure 2. Temperature dependence of in-plane electrical resistivity and Seebeck coefficient for 200 $\mathrm{nm}$ thick polycrystalline N-type layers prepared from $\mathrm{Yb}_{0.19} \mathrm{Co}_{4} \mathrm{Sb}_{12}$ target at $\mathrm{T}_{\mathrm{S}}=270^{\circ} \mathrm{C}, \mathrm{E}=4 \mathrm{~J} \cdot \mathrm{cm}^{-2}$ (for $13 \mathrm{~Pa}$ of argon: S-74 $=\mathrm{Yb}_{1.2} \mathrm{Co}_{24.2} \mathrm{Sb}_{74.5}$ ), and S-75 $=\mathrm{Yb}_{1.5} \mathrm{Co}_{26.1} \mathrm{Sb}_{72.4}$ for $0.1 \mathrm{~Pa}$ of argon).

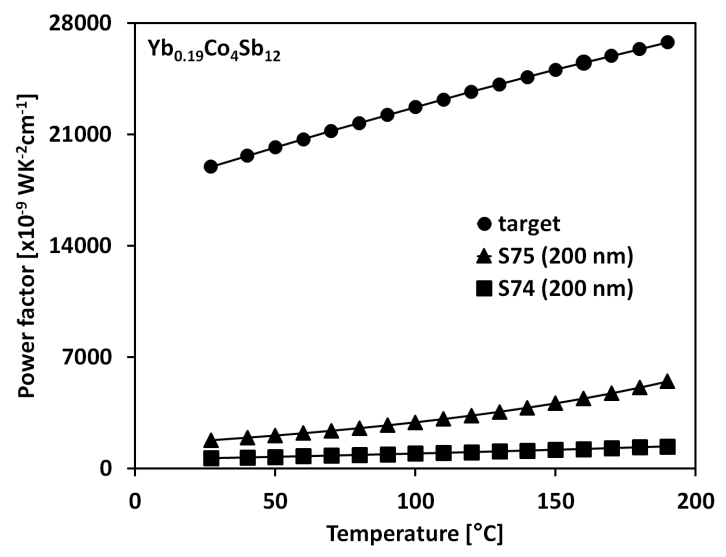

Figure 3. Calculated power factor vs. temperature dependency for polycrystalline (S-74 and S-75) and polycrystalline-stoichiometric (S-74) films prepared from $\mathrm{Yb}_{0.19} \mathrm{Co}_{4} \mathrm{Sb}_{12}$ target.

\subsubsection{PLD Deposition Regime (Figure 1(a))—FeSb 2 Te}

The structures were prepared from $\mathrm{FeSb}_{2} \mathrm{Te}$ hot pressed target in argon atmosphere (13 Pa). The best thermoelectric properties were obtained on the layers prepared at $\mathrm{T}_{\mathrm{S}}=250^{\circ} \mathrm{C}$ and $\mathrm{T}_{\mathrm{S}}=230^{\circ} \mathrm{C}$ with energy density $\mathrm{E}=3$ $\mathrm{J} \cdot \mathrm{cm}^{-2}$. Such layers were polycrystalline and P-type of electrical conductivity.Surface morphology was studied using the AFM working in the contact mode on a $\mathrm{FeSb}_{2.1} \mathrm{Te} 62 \mathrm{~nm}$ thick single layer prepared at $\mathrm{T}_{\mathrm{S}}=250^{\circ} \mathrm{C}$ with $E=3 \mathrm{~J} \cdot \mathrm{cm}^{-2}$. The $\mathrm{R}_{\mathrm{a}}$ of the $\mathrm{FeSb}_{2}$ Te layer calculated on $10 \times 10 \mu \mathrm{m}$ scan area was found to be $1.5 \mathrm{~nm}$ ). XRD experiments proved that both layers were well crystalline with peaks corresponding to the used PLD target. WDX experiments that were performed on the thicker layers proved average $\mathrm{FeSb}_{2} \mathrm{Te}$ stoichiometry corresponding very well to the target composition. The room temperature values of Seebeck coefficient of $\mathrm{FeSb}_{2} \mathrm{Te}_{\mathrm{O}}$ single layers prepared at $\mathrm{T}_{\mathrm{S}}=230^{\circ} \mathrm{C}$ with density $\mathrm{E}=3 \mathrm{~J} \cdot \mathrm{cm}^{-2}$ and $\mathrm{T}_{\mathrm{S}}=250^{\circ} \mathrm{C}$ are $105.6 \mu \mathrm{V} \cdot \mathrm{K}^{-1}$ and 119.0 $\mu \mathrm{V} \cdot \mathrm{K}^{-1}$, respectively. These values are about twice as high as the published values for bulk FeSb 2 Te material [4]. Prepared layers showed higher Seebeck coefficients in the whole studied temperature range from room temperature up to $500 \mathrm{~K}$ in comparison with values for bulk $\mathrm{FeSb}_{2} \mathrm{Te}$ material [5]. Temperature dependencies of the electrical resistivity and the Seebeck coefficient are depicted in Figure 4. Both layers showed semi-conducting P-type behaviour of electrical resistivity (the electrical resistivity decreases with rising temperature). The strong influence of deposition temperature $T_{S}$ on transport properties, especially on electrical resistivity was observed. The change of $T_{S}$ could cause different layer's stoichiometry. The room temperature values of electrical resistivity of the layers equal to $7.0 \mathrm{~m} \Omega \cdot \mathrm{cm}$ and $5.1 \mathrm{~m} \Omega \cdot \mathrm{cm}$ prepared at $T_{\mathrm{S}}=230^{\circ} \mathrm{C}$ and $\mathrm{T}_{\mathrm{S}}=250^{\circ} \mathrm{C}$, respectively were higher than the value published for bulk FeSb 2 Te material $\left(1.59 \mathrm{~m} \Omega \cdot \mathrm{cm}\right.$ at $\left.25^{\circ} \mathrm{C}\right)$ [4] and also higher than value measured on the PLD target $\left(2.5 \mathrm{~m} \Omega \cdot \mathrm{cm}\right.$ at $25^{\circ} \mathrm{C}$ ) (see Table 1). The layer prepared at $\mathrm{T}_{\mathrm{S}}=230^{\circ} \mathrm{C}$ demonstrated a lower room temperature value of the power factor $1593.1 \times 10^{-9} \mathrm{~W} \cdot \mathrm{K}^{-2} \cdot \mathrm{cm}^{-1}$ than the value published for bulk 


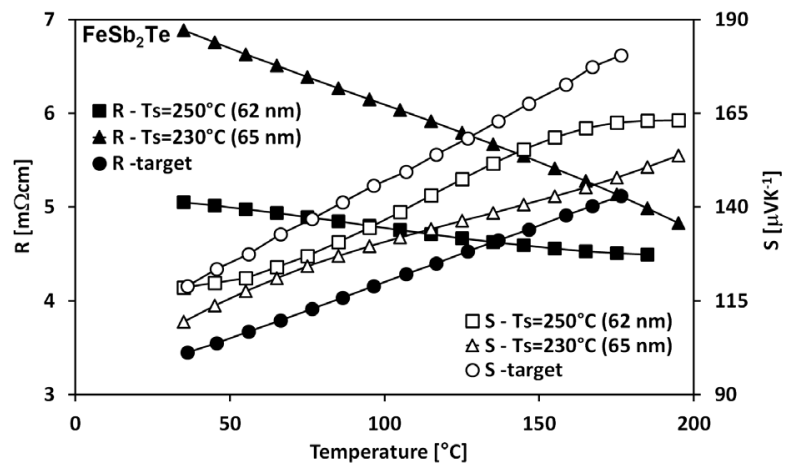

Figure 4. Temperature dependencies of electrical resistivity and the Seebeck coefficient of P-type layers prepared from the $\mathrm{FeSb}_{2}$ Te target with $\mathrm{E}=3 \mathrm{~J} \cdot \mathrm{cm}^{-2}$ at $\mathrm{T}_{\mathrm{S}}=230^{\circ} \mathrm{C}(65 \mathrm{~nm}$ in thickness $)$ and at $\mathrm{T}_{\mathrm{S}}=250^{\circ} \mathrm{C}(62 \mathrm{~nm}$ in thickness $)$ [6].

Table 1. Comparison of the room temperature values of in-plane electrical resistivity, the Seebeck coefficient and the power factor of PLD layers prepared at $T_{\mathrm{S}}=230^{\circ} \mathrm{C}$ with $\mathrm{E}=3 \mathrm{~J} \cdot \mathrm{cm}^{-2}$ and $\mathrm{T}_{\mathrm{S}}=250^{\circ} \mathrm{C}$ with $\mathrm{E}=3 \mathrm{~J} \cdot \mathrm{cm}^{-2}$ from FeSb $\mathrm{Te}_{2}$ target with bulk $\mathrm{FeSb}_{2}$ Te material [4].

\begin{tabular}{|c|c|c|c|c|}
\hline & Bulk FeSb $_{2}$ Te [4] & PLD target & $3 \mathrm{~J} \cdot \mathrm{cm}^{-2} 250^{\circ} \mathrm{C}$ & $3 \mathrm{~J} \cdot \mathrm{cm}^{-2} 230^{\circ} \mathrm{C}$ \\
\hline$R(\mathrm{~m} \Omega \cdot \mathrm{cm})$ & 1.59 & 2.5 & 5.1 & 7.0 \\
\hline$S\left(\mu \mathrm{V} \cdot \mathrm{K}^{-1}\right)$ & 54.70 & 113.5 & 119.0 & 105.6 \\
\hline$S^{2} / R\left(10^{-9} \times \mathrm{W} \cdot \mathrm{K}^{-2} \cdot \mathrm{cm}^{-1}\right)$ & 1881.82 & 5152.90 & 2776.70 & 1593.10 \\
\hline
\end{tabular}

material [4] [5] and also than the layers prepared at $\mathrm{T}_{\mathrm{S}}=250^{\circ} \mathrm{C}$. But the power factor's slope for the layer prepared at $T_{S}=230^{\circ} \mathrm{C}$ suggests that it may be comparable with layers prepared at $T_{S}=250^{\circ} \mathrm{C}$ for higher temperatures (above $500 \mathrm{~K}$ ). Room temperature ZT values published for bulk $\mathrm{FeSb}_{2} \mathrm{Te}$ [4] [5] materials are about 0.05 and 0.024 , respectively. We measured ZT of prepared single layers by Harman method. The measured room temperature value $\mathrm{ZT}$ value was always less than 0.1 . From the $\mathrm{ZT}$, we calculated thermal conductivity approximately $1.39 \mathrm{~W} \cdot \mathrm{K}^{-1} \cdot \mathrm{m}^{-1}$ and $0.80 \mathrm{~W} \cdot \mathrm{K}^{-1} \cdot \mathrm{m}^{-1}$ for layer prepared at $\mathrm{T}_{\mathrm{S}}=250^{\circ} \mathrm{C}$ and $\mathrm{T}_{\mathrm{S}}=230^{\circ} \mathrm{C}$, respectively. The resulting temperature dependency of the power factor for the best single PLD layers is depicted in Figure 5. Temperature dependency of the power factor of bulk $\mathrm{FeSb}_{2} \mathrm{Te}$ has never been published. Only available so far is the room temperature power factor of about $1881.8 \times 10^{-9} \mathrm{~W} \cdot \mathrm{K}^{-2} \cdot \mathrm{cm}^{-1}[4]$ [5].

\subsubsection{Off-Axis PLD Regime + Annealing (Figure 1(b))-FeSb 2 Te}

Several sets of $\mathrm{FeSb}_{2} \mathrm{Te}$ layers were prepared on fused silica and silicon substrates. Optimum conditions (smooth films, stoichiometry was reached for off-axis arrangement with $\mathrm{d}_{\mathrm{T}-\mathrm{S}}=30 \mathrm{~mm}, \mathrm{X}=0$, fluence of 2 $\mathrm{J} \cdot \mathrm{cm}^{-2}, 15 \mathrm{~Pa}$ of argon. Layers composition was $\mathrm{Fe}_{0.97} \mathrm{Sb}_{2} \mathrm{Te}_{1.1}$ (before annealing) and $\mathrm{Fe}_{1.00} \mathrm{Sb}_{2} \mathrm{Te}_{1.11}$ after RTA annealing $\left(800 \mathrm{~s}\right.$ at $\left.150^{\circ} \mathrm{C}\right)$.AFM scans showed homogeneous surface covered with droplets with diameter in the range of tenths of nanometres, rarely also covered with a droplet with height of approx. 200-300 nm, for illustration see Figure 6. Therefore, the roughness parameters strongly depends, if such feature is present or not. For $\mathrm{Fe}_{1.00} \mathrm{Sb}_{2} \mathrm{Te}_{1.11}$ layers $\mathrm{R}_{\mathrm{a}}$ parameter was between 1.4 and $6 \mathrm{~nm}$. The temperature dependencies of in-plane resistivity and Seebeck coefficient of $\mathrm{FeSb}_{2} \mathrm{Te}$ layers are presented in Figure 7. For FeSb $\mathrm{Fe}_{2}$ layers comparison to target material is also displayed. Additionally, in Figure 8 the calculated power factor is displayed. The layers prepared from both targets were found to be P-type semiconductors. It was determined from the positive sign of the Seebeck coefficient. All layers showed typical semiconducting behaviour which means the decreasing electrical resistivity with increasing temperature, with the room temperature values in the range from $5.7 \mathrm{~m} \Omega \cdot \mathrm{cm}$ to $11.7 \mathrm{~m} \Omega \cdot \mathrm{cm}$ in case of layers prepared from $\mathrm{FeSb}_{2} \mathrm{Te}$ target. Positive temperature dependencies were measured for the Seebeck coefficient, i.e. increasing Seebeck coefficient with temperature, with the room temperature absolute values from about $57 \mu \mathrm{V} \cdot \mathrm{K}^{-1}$ to $98 \mu \mathrm{V} \cdot \mathrm{K}^{-1}$ for $\mathrm{FeSb}_{2} \mathrm{Te}$. The very low room temperature ZT values determined by Harman method were found to be in the range from 0.06 to 0.08 for $\mathrm{FeSb}_{2} \mathrm{Te}$. From the $\mathrm{ZT}$, we calculated thermal conductivity approximately $0.30 \mathrm{~W} \cdot \mathrm{K}^{-1} \cdot \mathrm{m}^{-1} \mathrm{FeSb}_{2} \mathrm{Te}$. Our measured values (Figure 7 and Figure 8) for the layers prepared from $\mathrm{FeSb}_{2} \mathrm{Te}$ target are a bit different in comparison to older published results 


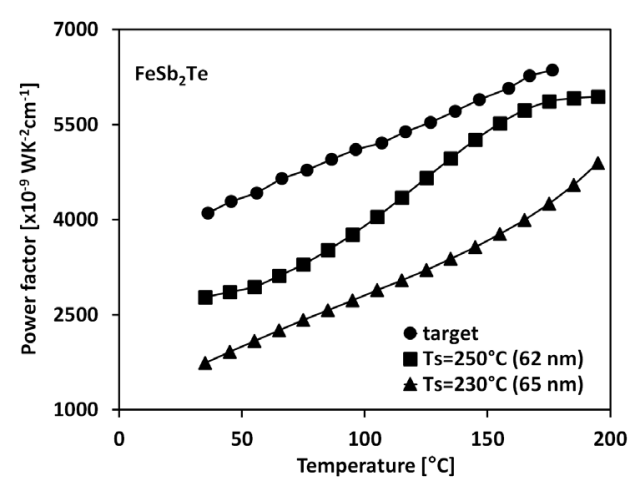

Figure 5. Temperature dependencies of the power factor for layers prepared from the FeSb 2 Te target with $\mathrm{E}=3 \mathrm{~J} \cdot \mathrm{cm}^{-2}$ at $\mathrm{T}_{\mathrm{S}}=230^{\circ} \mathrm{C}(65 \mathrm{~nm}$ in thickness; squares, sample $\mathrm{F}-14)$ and at $\mathrm{T}_{\mathrm{S}}=250^{\circ} \mathrm{C}(62 \mathrm{~nm}$ in thickness; triangles, sample F-10) [6].

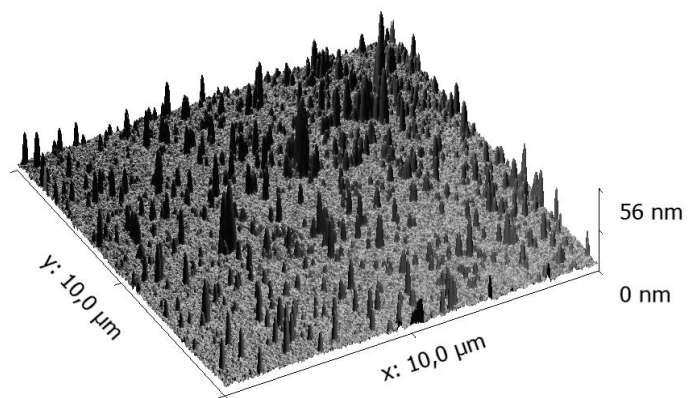

Figure 6. AFM image of $\mathrm{FeSb}_{2} \mathrm{Te}$ layer (Sample S-110).

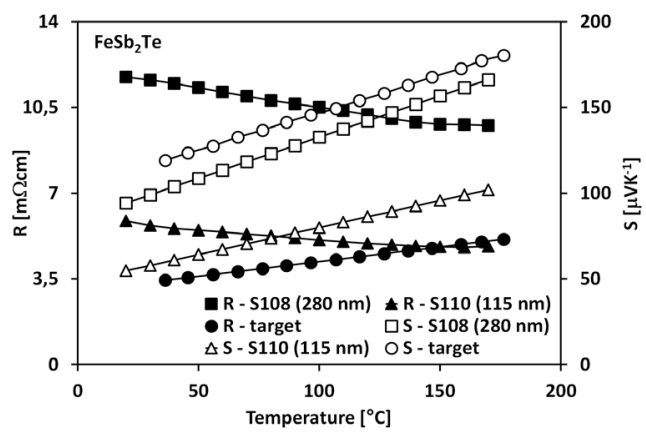

Figure 7. Temperature dependence of resistivity and Seebeck coefficient for layers of different thickness (S-110-thickness of $115 \mathrm{~nm}$ and S-108 thickness of $280 \mathrm{~nm}$ ) prepared from $\mathrm{FeSb}_{2}$ Te target with E $=2 \mathrm{~J} \cdot \mathrm{cm}^{-2}$ at $\mathrm{T}_{\mathrm{S}}=70^{\circ} \mathrm{C}$ and target material.

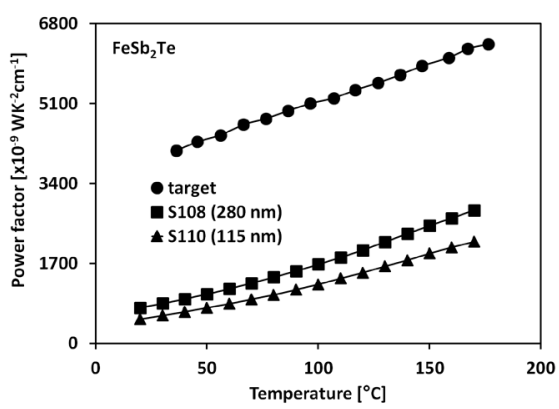

Figure 8. Temperature dependence of power factor for layers of different thickness (thickness of 115 $\mathrm{nm}$ and $280 \mathrm{~nm}$ ) prepared from FeSb${ }_{2}$ Te target with $\mathrm{E}=2 \mathrm{~J} \cdot \mathrm{cm}^{-2}$ at $\mathrm{T}_{\mathrm{S}}=70^{\circ} \mathrm{C}$ and target material. 
for bulk $\mathrm{FeSb}_{2} \mathrm{Te}$ [4]-[6] and we have found only limited data for similar layers. We can see that power factor of target if substantially higher compared to layers. On the other hand Tang et al. [3] reported values of about 3 $\mathrm{m} \Omega \cdot \mathrm{cm}$ and $110 \mu \mathrm{V} \cdot \mathrm{K}^{-1}$ at room temperature, which is $2-3$ times lower in case of resistivity and slightly higher in case of Seebeck coefficient. Both properties are strongly dependent on layer thickness.

\subsection{Single $\mathrm{Ce}_{0.1} \mathrm{Fe}_{0.7} \mathrm{Co}_{3.3} \mathrm{Sb}_{12}$ Layers}

\subsubsection{PLD Deposition Regime (Figure 1(a))- $\mathrm{Ce}_{0.1} \mathrm{Fe}_{0.7} \mathrm{Co}_{3.3} \mathrm{Sb}_{12}$}

The best single layer fabricated from $\mathrm{Ce}_{0.1} \mathrm{Fe}_{0.7} \mathrm{Co}_{3.3} \mathrm{Sb}_{12}$ target was prepared at $\mathrm{T}_{\mathrm{S}}=250^{\circ} \mathrm{C}$ for $\mathrm{E}=3 \mathrm{~J} \cdot \mathrm{cm}^{-2}$. The WDX composition study performed proved an average stoichiometry of $\mathrm{Ce}_{0.09} \mathrm{Fe}_{0.67} \mathrm{Co}_{3.33} \mathrm{Sb}_{12}$. The XRD measurement shown that the layers were well crystalline with $\mathrm{CoSb}_{3}$ structure. The layers exhibited semi-conducting P-type temperature behaviour of electrical resistivity. The measured value $9.8 \mathrm{~m} \Omega \cdot \mathrm{cm}$ was roughly 8.5 times higher at room temperature and roughly 5 times higher at $500 \mathrm{~K}$ in comparison with published bulk $\mathrm{Ce}_{0.12} \mathrm{Fe}_{0.71} \mathrm{Co}_{3.29} \mathrm{Sb}_{12}$ data [3]. The room temperature value of the measured Seebeck coefficient of the layer 89.4 $\mu \mathrm{V} \cdot \mathrm{K}^{-1}$ was roughly 1.4 times higher in comparison with bulk $\mathrm{Ce}_{0.12} \mathrm{Fe}_{0.71} \mathrm{Co}_{3.29} \mathrm{Sb}_{12}$ [3] but we observed a lower temperature slope, thus the measured value is comparable with the published bulk material value at $500 \mathrm{~K}$ [3]. Temperature dependencies of electrical resistivity and Seebeck coefficient are depicted in Figure 9. The resulting dependency of the power factor versus temperature for the best single PLD layers is together with the published bulk $\mathrm{Ce}_{0.12} \mathrm{Fe}_{0.71} \mathrm{Co}_{3.29} \mathrm{Sb}_{12}$ data [3] are depicted in Figure 10. The power factors of our best prepared single layers are much smaller (roughly twice smaller at room temperature and roughly 5 times smaller at $500 \mathrm{~K}$ )

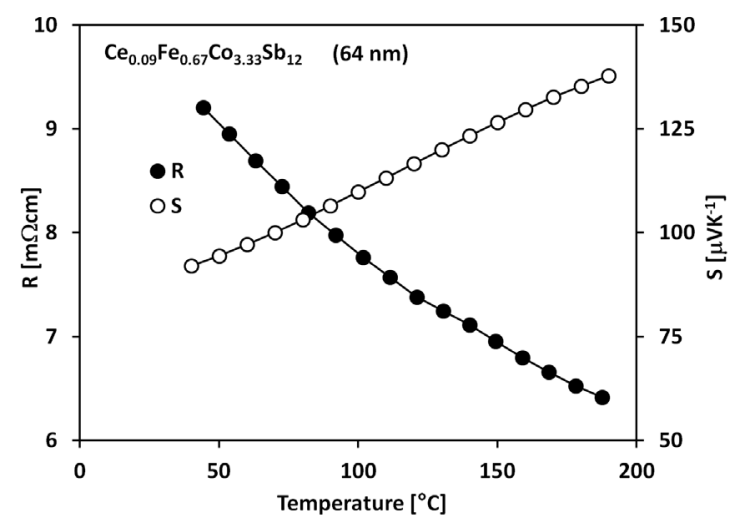

Figure 9. Temperature dependencies of in-plane electrical resistivity (filled circles) and the Seebeck coefficient (empty circles) for the $64 \mathrm{~nm}$ thick P-type layer prepared from the $\mathrm{Ce}_{0.1} \mathrm{Fe}_{0.7} \mathrm{Co}_{3.3} \mathrm{Sb}_{12}$ target at $\mathrm{T}_{\mathrm{S}}=$ $250^{\circ} \mathrm{C}$ with $\mathrm{E}=3 \mathrm{~J} \cdot \mathrm{cm}^{-2}[6]$.

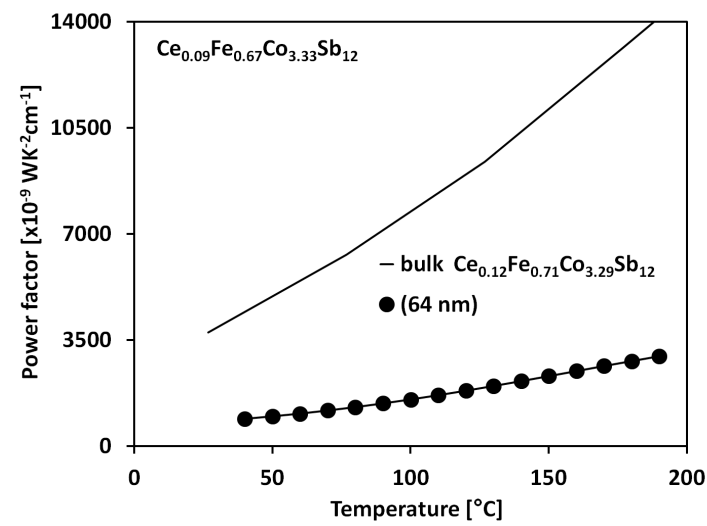

Figure 10. Temperature dependencies of the power factor (empty squares) for the $64 \mathrm{~nm}$ thick P-type layer prepared from the $\mathrm{Ce}_{0.1} \mathrm{Fe}_{0.7} \mathrm{Co}_{3.3} \mathrm{Sb}_{12}$ target at $\mathrm{T}_{\mathrm{S}}=250^{\circ} \mathrm{C}$ with $\mathrm{E}=3 \mathrm{~J} \cdot \mathrm{cm}^{-2}$ and for $\mathrm{Ce}_{0.12} \mathrm{Fe}_{0.71} \mathrm{Co}_{3.29} \mathrm{Sb}_{12}$ bulk material [3] [6]. 
(see Figure 10) in comparison with bulk $\mathrm{Ce}_{0.12} \mathrm{Fe}_{0.71} \mathrm{Co}_{3.29} \mathrm{Sb}_{12}$ [3]. Room temperature $\mathrm{ZT}$ values published for bulk $\mathrm{Ce}_{0.12} \mathrm{Fe}_{0.71} \mathrm{Co}_{3.29} \mathrm{Sb}_{12}$ [3] materials are about 0.05 . The values of $\mathrm{ZT}=0.8$ at $\mathrm{T}=750 \mathrm{~K}$ for bulk $\mathrm{Ce}_{0.12} \mathrm{Fe}_{0.71} \mathrm{Co}_{3.29} \mathrm{Sb}_{12}$ [3], $\mathrm{ZT}=1.1$ at $\mathrm{T}=750 \mathrm{~K}$ for bulk $\mathrm{Ce}_{0.28} \mathrm{Fe}_{1.5} \mathrm{Co}_{2.5} \mathrm{Sb}_{12}$ [7] was published in the literature. Theoretical maximum ZT $=1.4$ at $1000 \mathrm{~K}$ was predicted for $\mathrm{Ce}_{0.9} \mathrm{Fe}_{3} \mathrm{CoSb}_{12}$ [8]). We measured ZT of prepared single layers by Harman method. The measured room temperature value ZT value was always less than 0.1. Fromthe ZT, we estimated thermal conductivity approximately $0.50 \mathrm{~W} \cdot \mathrm{K}^{-1} \cdot \mathrm{m}^{-1}$.

\subsubsection{Off-Axis PLD + Annealing- $\mathrm{Ce}_{0.1} \mathrm{Fe}_{0.7} \mathrm{Co}_{3.3} \mathrm{Sb}_{12}$}

Several sets of $\mathrm{Ce}_{0.12} \mathrm{Fe}_{0.71} \mathrm{Co}_{3.29} \mathrm{Sb}_{12}$ layers were prepared by PLD technique combined with post deposition RTA on fused silica and silicon substrates. Argon pressure was changed from $0.5 \mathrm{~Pa}$ to $50 \mathrm{~Pa}$ and fluence from 1 to $3 \mathrm{~J} \cdot \mathrm{cm}^{-2}$. Optimum conditions (smooth, stoichiometric films) were prepared for: target-substrate distance $\mathrm{d}_{\mathrm{T}-\mathrm{s}}$ $=30 \mathrm{~mm}$, fluence of $2 \mathrm{~J} \cdot \mathrm{cm}^{-2}, 15 \mathrm{~Pa}$ of argon, followed by annealing for $800 \mathrm{~s}$ at $150^{\circ} \mathrm{C}$. Films were very smooth-see Figure 11 and Figure 12. Parameter $R_{a}$ measured by AFM was $1.38 \mathrm{~nm}$. The temperature dependence of electrical resistivity and Seebeck coefficient is in Figure 13. We can observe some difference in properties for layers of different thickness. Temperature dependence of power factor is shown in Figure 14. From ZT we calculated thermal conductivity approximately $0.35 \mathrm{~W} \cdot \mathrm{K}^{-1} \cdot \mathrm{m}^{-1}$. It is important to mention that the measured value of $\mathrm{ZT}$ is close to resolution limit of the method and so the measured results of $\mathrm{ZT}$ and calculated thermal conductivity are rather informative.

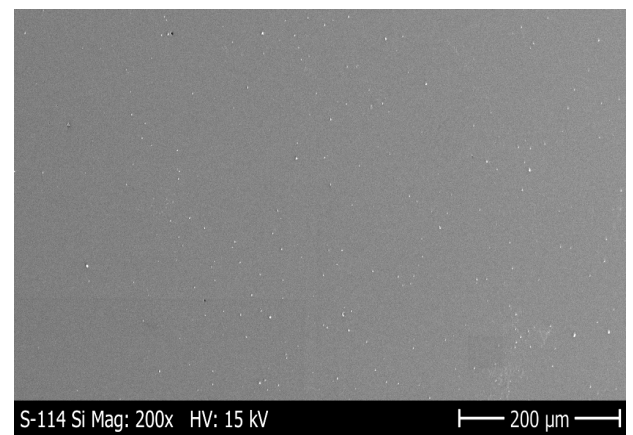

Figure 11. $\mathrm{SEM}$ photo of $\mathrm{Ce}_{0.09} \mathrm{Fe}_{0.67} \mathrm{Co}_{3.33} \mathrm{Sb}_{12}$ (layer $\mathrm{S}-114$ ).

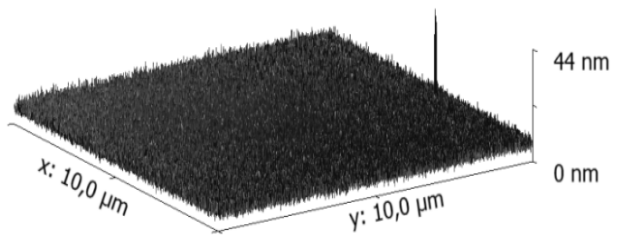

Figure 12. AFM image of $\mathrm{Ce}_{0.09} \mathrm{Fe}_{0.67} \mathrm{Co}_{3.33} \mathrm{Sb}_{12}$ layer (S-116 Si).

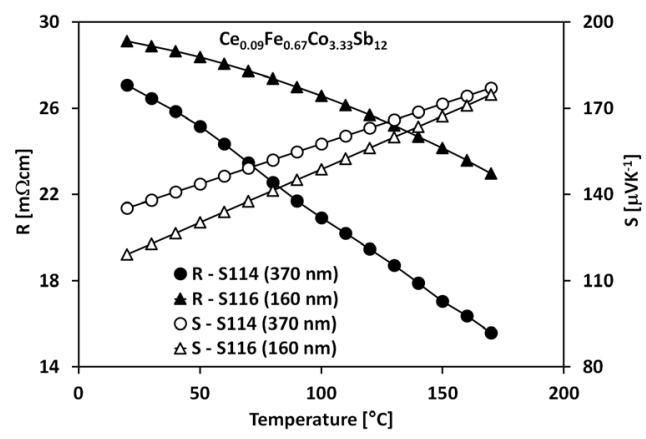

Figure 13. Temperature dependencies of electrical resistivity (squares) and the Seebeck coefficient (triangles) for the $160 \mathrm{~nm}$ and $370 \mathrm{~nm}$ thick P-type layers prepared from the $\mathrm{Ce}_{0.1} \mathrm{Fe}_{0.7} \mathrm{Co}_{3.3} \mathrm{Sb}_{12}$ target at $\mathrm{T}_{\mathrm{S}}=250^{\circ} \mathrm{C}$ with $\mathrm{E}=3 \mathrm{~J} \cdot \mathrm{cm}^{-2}$. 


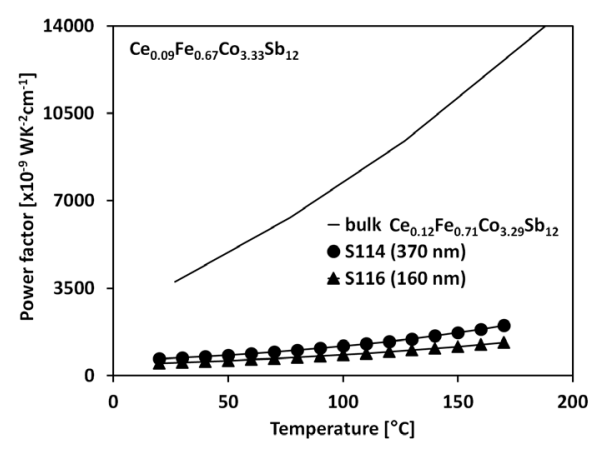

Figure 14. Temperature dependencies of power factor for the $160 \mathrm{~nm}$ (triangles) and $370 \mathrm{~nm}$ (squares) thick P-type layers prepared from the $\mathrm{Ce}_{0.1} \mathrm{Fe}_{0.7} \mathrm{Co}_{3.3} \mathrm{Sb}_{12}$ target at $\mathrm{T}=250^{\circ} \mathrm{C}$ with $\mathrm{E}=3 \mathrm{~J} \cdot \mathrm{cm}^{-2}$ and for $\mathrm{Ce}_{0.12} \mathrm{Fe}_{0.71} \mathrm{Co}_{3.29} \mathrm{Sb}_{12}$ bulk material [3].

\subsection{Multilayered Structures}

We believe that cross-plain thermoelectric properties of a multi-layered system should be superior or comparable to the properties of single thin layers, if proper deposition conditions are used. An improvement of cross-plainthermal conductivity of the multilayered systems is expected mainly due to an increased number of interfaces (scattering mechanisms).Transport properties such as a Seebeck coefficient and electrical conductivity might not beheavily affected, thus the overall thermoelectric properties (figure of merit) could be expected improve as well. To build multi-layered structure the two semiconducting materials of the same conductivity type and similar lattice constants are needed. The difference in the lattice constants would cause the tension and the thin layers could crack and delaminate. By using materials of different conductivity we build potential barriers and PN junction properties would dominate. These reasons lead us to utilize $\mathrm{FeSb}_{2} \mathrm{Te}$ and $\mathrm{Ce}_{0.1} \mathrm{Fe}_{0.7} \mathrm{Co}_{3.3} \mathrm{Sb}_{12}$ thermoelectric P-type conductivity semiconducting materials for creation of multi-layered structures-see Figure 15. We created multilayers thickness of: $\mathrm{n}(\mathrm{x} 3)=150 \mathrm{~nm}$ or $300 \mathrm{~nm}$ (consisted from $3 \mathrm{~nm}$ layers of $\mathrm{x} 1$ and $\mathrm{x} 2$ - see Figure 16), and multilayers of $\mathrm{n}(\mathrm{x} 3)=150 \mathrm{~nm}$ and $300 \mathrm{~nm}$ (consisted from $50 \mathrm{~nm}$ layers of $\mathrm{x} 1 \mathrm{and} \mathrm{x} 2$ ). Example of XRD structure is in Figure 17. XRD of multilayered samples showed structure similar to $\mathrm{CoSb}_{3}$, with slightly shifted peaks. The shift increases with angle, which implies larger inter-atomic distances. Since the SIMS method confirmed separation of layers this could be attributed to the effect of the $\mathrm{FeSb}_{2} \mathrm{Te}$ amorphous material between $\mathrm{Ce}_{0.1} \mathrm{Fe}_{0.7} \mathrm{Co}_{3.3} \mathrm{Sb}_{12}$ crystalline layers. The multilayers ( $3 \mathrm{~nm}$ period) topology was homogenous with occasional droplet with heights around $100 \mathrm{~nm}$. There was a doubt if the layers are separated and crystalline after annealing process. Using SEM (Leo 1550 (Zeiss), FEI Quanta 3D FEG, Tescan FERA3) we were not able to confirm sublayers separation. That was a reason why new multilayers (double layers (S-127), and sixth layers (S-128) system) consisted of $50 \mathrm{~nm}$ sublayers of $\mathrm{Ce}_{0.1} \mathrm{Fe}_{0.67} \mathrm{Co}_{3.3} \mathrm{Sb}_{12} / \mathrm{FeSb}_{2} \mathrm{Te}$. $(50 \mathrm{~nm} / 50 \mathrm{~nm}$ ) were prepared and finally studied by SIMS, which showed little difference between layers before and after annealing. In both cases it is possible to observe (see Figure 18) layers separation, especially on Ce, Co, Te elements, where we observe sharp interfaces. Generally, the interfaces are always distorted by atom mixing effects and in some cases by ion induced chemical segregation. Closer details see [9]. From $10 \times 10 \mu \mathrm{m}$ scans, $\mathrm{R}_{\mathrm{a}}$ was $1.41 \mathrm{~nm}$.

Example of surface imaging is in Figure 16. Measured temperature dependencies of in-plane electrical resistivity and Seebeck coefficient of ML systems are depicted in Figure 19 and Figure 20, respectively. Both studied multi-layered structures shoved P-type semiconducting behaviour of electrical resistivity and the Seebeck coefficient-the electrical resistivity decreases with rising temperature and positive sign of the Seebeck coefficient. This was expected, because the single layers of individual materials were proved $\mathrm{P}$ type, too. Both multi-layered structures shoved practically the same values of electrical resistivity and the Seebeck coefficient. Transport properties of similar single layers and multi-layered systems were in detail published recently [6]. The multi-layered systems shoved higher Seebeck coefficient than the single layers of individual materials, but it shoved also higher electrical resistivity than the single layers which was unexpected and is now under study. The carrier scattering on the layer interfaces or on the surface should not have such a heavy effect. With assumption of stoichiometric transfer from PLD target during deposition and no impact of annealing after PLD on final composition, we should see lower or comparable absolute values of electrical resistivity of multi-layered 


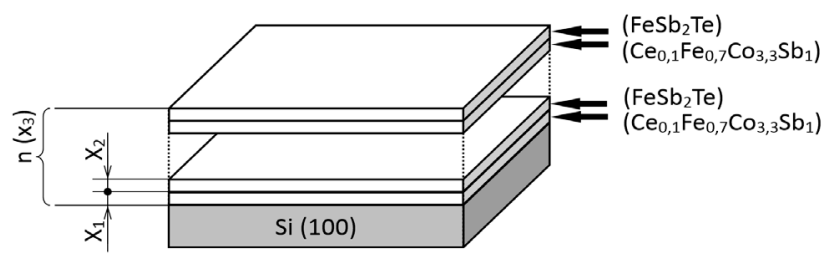

Figure 15. Schema of fabricated multilayer system.

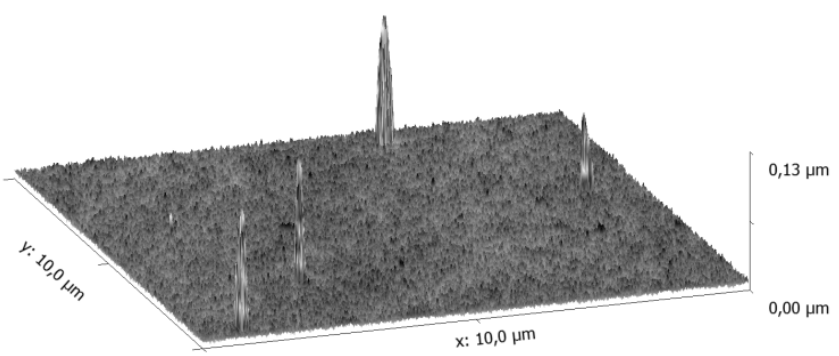

Figure 16. AFM image of multilayered structure (layer S-123, $150 \mathrm{~nm}$ thick, 50 layers, FeSb 2 Te on the top). $\mathrm{R}_{\mathrm{a}}=1.41 \mathrm{~nm}$ (scan $10 \times 10 \mu \mathrm{m}$ ). From the topology point of view the multilayers were homogeneous, with occasional droplet with heights around $100 \mathrm{~nm}$.

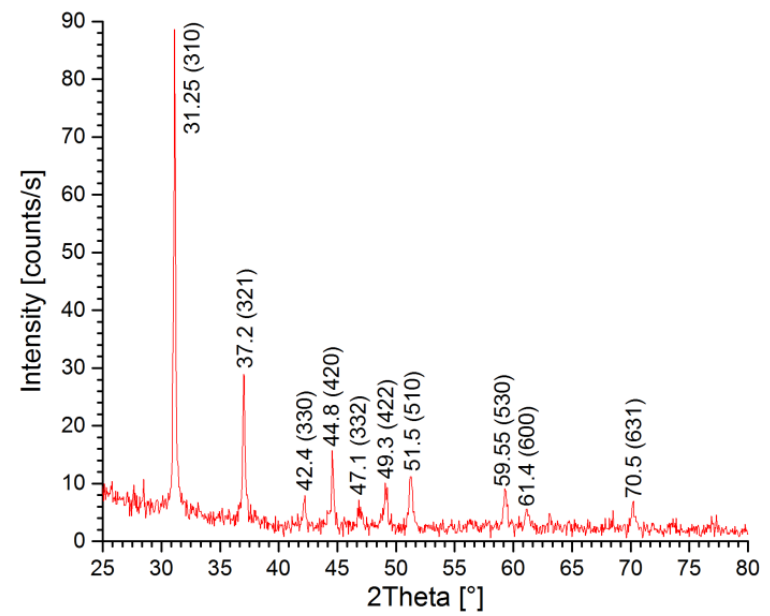

Figure 17. XRD spectra of multilayered structure (layer S 125, FS, 300 nm thick (100 layers)), after annealing. Peak values correspond with shifted $\mathrm{CoSb}_{3}$ structure.

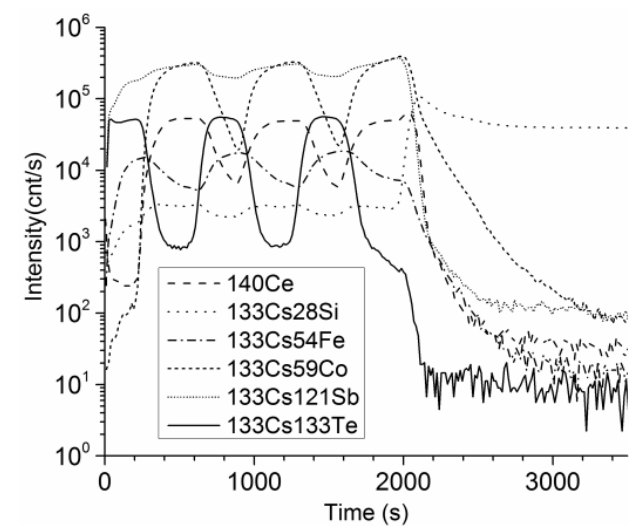

Figure 18. SIMS profiles of multilayered structure annealed at $100^{\circ} \mathrm{C}$ for 10 minutes. 


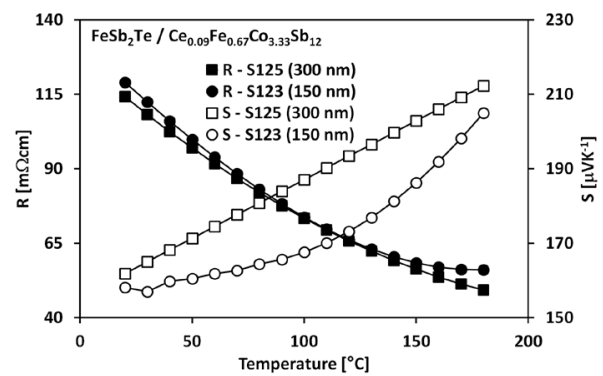

Figure 19. Temperature dependence of electrical resistivity and Seebeck coefficient for multilayers: layer $150 \mathrm{~nm}$ thick (50 layers) (S-123) and $300 \mathrm{~nm}$ thick (100 layers) (S-125). Multi-layered system consisted of $3 \mathrm{~nm} / 3 \mathrm{~nm}$ layers of $\mathrm{Ce}_{0.1} \mathrm{Fe}_{0.67} \mathrm{Co}_{3.3} \mathrm{Sb}_{12} / \mathrm{FeSb}_{2} \mathrm{Te}$. Films (S-123 and S-125) were fabricated by PLD $\left(\mathrm{T}_{\mathrm{S}}=70^{\circ} \mathrm{C}\right)$ followed with RTA annealing at $150^{\circ} \mathrm{C}$ for $800 \mathrm{~s}$.

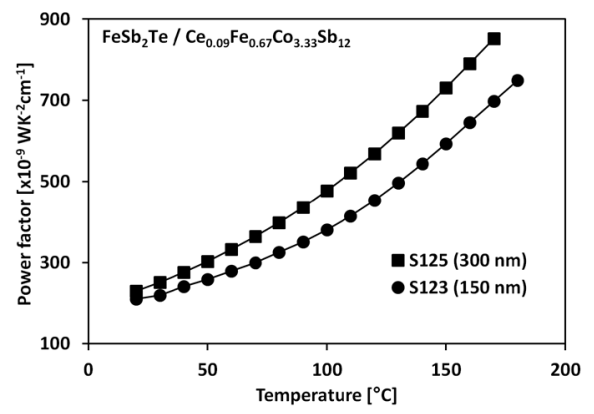

Figure 20. Temperature dependence of power factor for multilayers: layer $150 \mathrm{~nm}$ thick (50 layers) (S-123) and $300 \mathrm{~nm}$ thick (100 layers) (S-125). Multi-layered system consisted of $3 \mathrm{~nm} / 3 \mathrm{~nm}$ layers of $\mathrm{Ce}_{0.1} \mathrm{Fe}_{0.67} \mathrm{Co}_{3.3} \mathrm{Sb}_{12} / \mathrm{FeSb}_{2} \mathrm{Te}$. Films (S-123 and S-125) were fabricated by PLD $\left(\mathrm{T}_{\mathrm{S}}=70^{\circ} \mathrm{C}\right)$ followed with RTA annealing at $150^{\circ} \mathrm{C}$ for $800 \mathrm{~s}$.

system and single layers, which was observed in the past [6]. We are not sure about crystallinity if the structure and additional study is needed to understand this phenomenon. Due to observed increase of electrical resistivity is the resultant power factor of multi-layered limit of used approach. From ZT, electrical resistivity and Seebeck coefficient we estimated the room temperature system lower than power factors of individual single layers (see Figure 8 and Figure 14). For multi-layered systems we measured ZT about 0.06 . For single $\mathrm{FeSb}_{2} \mathrm{Te}$ and $\mathrm{Ce}_{0.1} \mathrm{Fe}_{0.67} \mathrm{Co}_{3.33} \mathrm{Sb}_{12}$ layers we observed similar $\mathrm{ZT}$ values in the range from 0.06 to 0.07 and from 0.04 to 0.06 , respectively. The values are close to the resolution thermal conductivity $0.10 \mathrm{~W} \cdot \mathrm{K}^{-1} \cdot \mathrm{m}^{-1}$ for multi-layered system, $0.30 \mathrm{~W} \cdot \mathrm{K}^{-1} \cdot \mathrm{m}^{-1}$ and $0.35 \mathrm{~W} \cdot \mathrm{K}^{-1} \cdot \mathrm{m}^{-1}$ for single $\mathrm{FeSb}_{2} \mathrm{Te}$ and $\mathrm{Ce}_{0.1} \mathrm{Fe}_{0.67} \mathrm{Co}_{3.33} \mathrm{Sb}_{12}$ layers, respectively. The decrease of the thermal conductivity can be caused by introduced interfaces, but due to low ZT it is just a rough estimate. If we compare the multi-layered system with the single layers from thermoelectric point of view and just based on the presented data, one can conclude that the multi-layered structures seems to be very similar to the best single layers (very similar or the same ZT). The multi-layered system exhibits lower thermal conductivity (3.5 times) and higher Seebeck coefficient, but unfortunately also much higher electrical resistivity and so lower resultant power factor (3.5 times) in comparison to the best single layers. These effects somehow compensate them self and so overall ZT stays the same. When we compare parameters of multilayers with earlier results [6] we can conclude that thermoelectric properties of multilayers are extremely dependent on final multilayer thickness, period of layers and technology of layers fabrication. Our results indicate that thermal conductivity of multilayers is lower than single layers.

\subsection{Characterisation with Thermal Microscope}

To compare studied layers from thermal conductivity point of view a simple relative method using Atomic Force Thermal Microscope (AFMTh) was developed. The method evaluates thermal signal response obtained on the steep step silicon/evaporate layer interface. The measured thermal response on the silicon substrate is taken as a reference one, while the obtained thermal responses observed on the different materials of the same thick- 
ness one can directly relatively compare from thermal conductivity point of view, i.e. the raw information about the layer's thermal conductivity is inherent in the thermal response. To obtain appropriate interface, with a steep edge between the reference silicon layer and the deposited material layer, ion induced milling process controlled by Time Of Flight-Secondary Ion Mass Spectrometer (TOF-SIMS) was involved. Several $200 \mu \mathrm{m} \times 200 \mu \mathrm{m}$ craters were milled off exactly to Si/evaporated materialto obtain appropriate interface, with a steep edge between the reference silicon layer and the deposited material layer. Ion induced milling process controlled by Time Of Flight-Secondary Ion Mass d Si/layer boundary, thus we expect that evaporated layer has the homogeneous thickness. The whole process was performed in SEM-FIB-GIS-SIMS Lyra TESCAN apparatus, equipped with the $\mathrm{Ga}^{+}$ion gun. For the thermal characterization of our samples a current pulse method was used. A typical image of measured topography and corresponding thermal signal is shown in Figure 21 for the $\mathrm{Bi}_{2} \mathrm{Te}_{3}$ layer, the left-hand side shows the topography image and the right-hand side shows the corresponding thermal signal. The $\mathrm{Si}$ and $\mathrm{Bi}_{2} \mathrm{Te}_{3}$ parts of the sample are also marked in the image. The discontinuity of the thermal signal $(-100 \mu \mathrm{m})$ on the straight edge is due to the parasitic heat flow through the air surrounding the tip, which was discussed elsewhere [10].

As the samples are prepared on the same substrate and undergo the same pre-measurement procedures, while the measurement parameters and conditions are also set to identical values, we can take the value of the relative change of thermal signal on the Si part as a reference. Numerical values of the relative change of thermal signal for $\mathrm{Si}$ and layers are taken in sufficient distance from the edge, where the signal is equalized. Computed differences of these levels is directly proportional to the thermal resistivity of the measured material and its dependence on the thickness of layers for all $\mathrm{Yb}_{0.19} \mathrm{Co}_{4} \mathrm{Sb}_{12}, \mathrm{FeSb}_{2} \mathrm{Te}, \mathrm{Ce}_{0.1} \mathrm{Fe}_{0.7} \mathrm{Co}_{3.3} \mathrm{Sb}_{12}, \mathrm{Bi}_{2} \mathrm{Te}_{3}$ single layers and $\mathrm{FeSb}_{2} \mathrm{Te} / \mathrm{Ce}_{0.1} \mathrm{Fe}_{0.7} \mathrm{Co}_{3.3} \mathrm{Sb}_{12}$ multi-layered structure are shown in Figure 22. The depicted dependence on the layer thickness has a linear character for all materials except $\mathrm{FeSb}_{2} \mathrm{Te}$ single layers and $\mathrm{FeSb}_{2} \mathrm{Te}$ /

$\mathrm{Ce}_{0.1} \mathrm{Fe}_{0.7} \mathrm{Co}_{3.3} \mathrm{Sb}_{12}$ multilayers, where most probably the excess of $\mathrm{Sb}$ for thicker layers takes part.

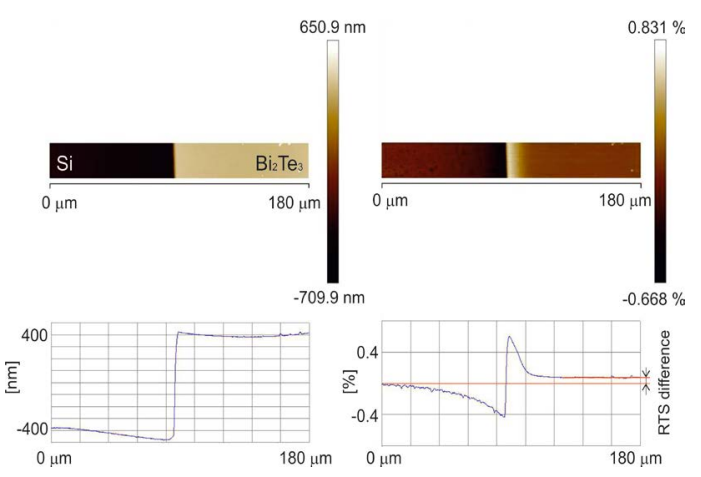

Figure 21. Surface topography (on the left-hand side) and corresponding relative change of thermal signal (on the right-hand side) with corresponding step profiles from the whole area (128 scans) for the edge of the etched hole on the $\mathrm{Bi}_{2} \mathrm{Te}_{3}$ layer with a thickness of $900 \mathrm{~nm}$. Relative thermal signal (RTS) difference is marked.

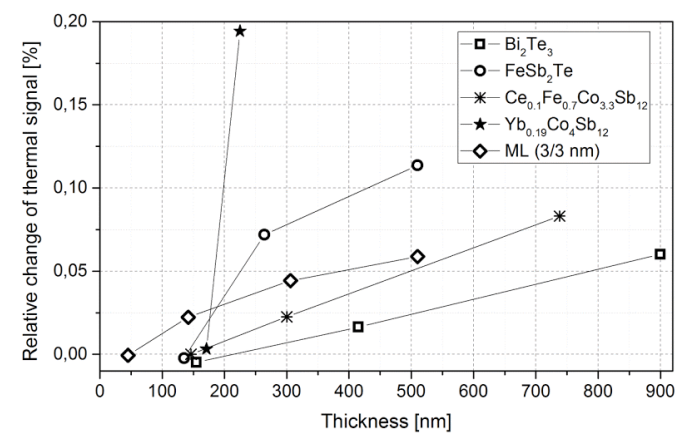

Figure 22. Dependence of the relative change of the thermal signal on the layer thickness are shown for $\mathrm{Bi}_{2} \mathrm{Te}_{3}, \mathrm{FeSb}_{2} \mathrm{Te}, \mathrm{Ce}_{0.1} \mathrm{Fe}_{0.7} \mathrm{Co}_{3.3} \mathrm{Sb}_{12}, \mathrm{Yb}_{0.19} \mathrm{Co}_{4} \mathrm{Sb}_{12}$ and $\mathrm{FeSb}_{2} \mathrm{Te} / \mathrm{Ce}_{0.1} \mathrm{Fe}_{0.7} \mathrm{Co}_{3.3} \mathrm{Sb}_{12}$ multilayers respectively. 


\section{Conclusion}

Thermoelectric single layers as $\mathrm{Bi}_{2} \mathrm{Te}_{3}, \mathrm{Yb}_{\mathrm{x}} \mathrm{Co}_{4} \mathrm{Sb}_{12}, \mathrm{FeSb}_{2} \mathrm{Te}, \mathrm{Ce}_{0.1} \mathrm{Fe}_{0.7} \mathrm{Co}_{3.3} \mathrm{Sb}_{12}$ and multilayers of $\mathrm{Ce}_{0.1} \mathrm{Fe}_{0.7} \mathrm{Co}_{3.3} \mathrm{Sb}_{12}$ and $\mathrm{FeSb}_{2} \mathrm{Te} / \mathrm{Ce}_{0.1} \mathrm{Fe}_{0.7} \mathrm{Co}_{3.3} \mathrm{Sb}_{12}$ were prepared by PLD or combination of PLD with RTA. Smooth, polycrystalline, stoichiometric layers were fabricated. To obtain very smooth morphology for multilayers the off- axis PLD followed by RTA is preferable. In that configuration is necessary carefully optimize annealing parameters. We used SIMS technique to identify the separation of layers in multilayers. Measured physical and thermoelectrical properties depend on deposition conditions and films parameters (as thickness and stoichiometry). Multilayers systems exhibited lower value of thermal conductivity, compared to single layers. ZT of ML and single layers was low and roughly comparable. PLD of multilayers can bring technological problems with layers roughness, but off axis deposition with subsequent annealing brings problems of annealing optimization. It is hard to decide if ML systems are better compared to single layers. Optimization of deposition process, physical parameters and thickness layers play an important role in ZT and values. After careful optimization of single layers deposition it is possible to study advantages or disadvantages ML system. Feasibility of the relative thermal conductivity measurement with the new electronic instrument working in pulsed current mode is demonstrated. The laser deposition methods are suitable tools for fast and cheap study of wide scale of parameters having influence on final thermoelectric properties.

\section{Acknowledgements}

The project has been supported by Czech Grant Agency under GA13-33056S, project SUSEN CZ.1.05/2.1.00/ 03.0108 (ERDF) and the Grant Agency of the Czech Technical University in Prague under grant No. SGS14/168/OHK4/2T/17.

\section{References}

[1] Goncalves, L. M., Couto, C., Alpuim, P., Rowe, D.M. and Correia, J.H. (2006) Thermoelectric Properties of $\mathrm{Bi}_{2} \mathrm{Te}_{3} / \mathrm{Sb}_{2} \mathrm{Te}_{3}$ Thin Films. Materials Science Forum, 514-516, 156-160. http://dx.doi.org/10.4028/www.scientific.net/MSF.514-516.156

[2] Yang, J., Hao, Q., Wang, H., Lan, Y.C., He, Q.Y., Minnich A., et al. (2009) Solubility Study of Yb in n-Type Skutterudites $\mathrm{Yb}_{\mathrm{x}} \mathrm{Co}_{4} \mathrm{Sb}_{12}$ and Their Enhanced Thermoelectric Properties. Phys Rev B, 80, 115329. http://dx.doi.org/10.1103/PhysRevB.80.115329

[3] Tang, X.F., Chen, L., Goto, T., Hirai, T. and Yuan, R.Z. (2001) Synthesis and Thermoelectric Properties of Filled Skutterudite Compounds $\mathrm{Ce}_{\mathrm{y}} \mathrm{Fe}_{\mathrm{x}} \mathrm{Co}_{4-\mathrm{x}} \mathrm{Sb}_{12}$ by Solid State Reaction. J Mater Sci, 36, 5435-5439. http://dx.doi.org/10.1023/A:1012473428845

[4] Fleurial, J.P. (1998) Advanced Thermoelectric Materials with Enhanced Crystal Lattice Structure and Methods of Preparation. US Patent 5.747.728.

[5] Semeniouk, V. and Fleurial, J.P. (1997) Novel High Performance Thermoelectric Microcoolers with Diamond Substrates. Proc. 16th Int. Conf. Thermoelectrics, Dresden, Germany, 26-29 August, 683-686. http://dx.doi.org/10.1109/ict.1997.667622

[6] Zeipl, R., Jelinek, M., Navratil, J., Kocourek, T., Leshkov, S., Sroubek, F., et al. (2013) Properties of Thermoelectric $\mathrm{Ce}_{0.09} \mathrm{Fe}_{0.67} \mathrm{Co}_{3.33} \mathrm{Sb}_{12} / \mathrm{FeSb}_{2} \mathrm{Te}$ Multi-Layered Structures Prepared by Laser Ablation. Thin Solid Films, 548, $590-596$. http://dx.doi.org/10.1016/j.tsf.2013.09.068

[7] Tang, X.F., Zhang, Q., Chen, L., Goto, T. and Hirai, T. (2005) Synthesis and Thermoelectric Properties of p-Type- and n-Type-Filled Skutterudite RyMxCo4-x Sb12(R:Ce,Ba,Y;M:Fe,Ni). J. Appl. Phys., 97, 093712. http://dx.doi.org/10.1063/1.1888048

[8] Sales, B.C., Mandrus, B., Chakoumakos, B.C., Keppens, J. and Thompson, J.R. (1997) Filled Skutterudite Antimonides: Electron Crystals and Phonon Glasses. Phys. Rev. B, 56, 15081. http://dx.doi.org/10.1103/PhysRevB.56.15081

[9] Lorinčík, J., Veselá, D., Jelinek, M., Remsa, J., Zeipl, R., Vaniš, J. and Kocourek, T. (2016) SIMS Study of Laser Prepared Thermoelectric Multilayers. Applied Surface Science, unpublished.

[10] Puyoo, E., Grauby, S., Rampnoux, J.M., Rouviere, E. and Dilhaire, S. (2010) Thermal Exchange Radius Measurement: Application to Nanowire Thermal Imaging. Review of Scientific Instruments, 81, 073701. http://dx.doi.org/10.1063/1.3455214 